\section{Sulphanilamide Therapy in Pneumonia}

Nrcotinic acid has been found to be especially important as a supplement to sulphanilamide therapy of pneumonia. In a series of cases, it has been noted that there frequently occurs in victims of pneumonia treated with sulphanilamide, a black-dotted, heavy furring of the tongue akin to black-tongue. At the same time, consolidation of the lung fails to resolve though the temperature be normal and toxic effects cleared.

Administration of nicotinic acid in doses of 10-100 mgm. results in rapid clearing of the tongue, generally from behind forward. At the same time, the consolidation of the lung resolves.

Though no pathological studies have been made, it appears probable that the failure of resolution in these cases is due to changes in the mucous membrane of the bronchial tree of the same character as affects the tongue.

An interesting light is thrown on the mechanism of action of sulphanilamide by the change of typing of the pneumococci in cases treated with the drug. Following therapy, it will frequently be found that the pneumococci lose their typing reactions and cannot be typed. Characteristic typing reactions are usually restored to the organisms after animal passage.

Emanuel M. Josephson. Gutel KLEWAN.

108 East Eighty-first Street,

New York.

March 6.

\section{"Animal Language"}

THERE is a point in the review of "Animal Language" in NATURE of February 25 on which I should like to comment. The reviewer writes : "At times, Dr. Huxley expresses his views with considerable confidence. "What is the point of a rattlesnake's rattling ? The answer is really very simple. The snake doesn't want to strike unless it has to. It might very easily get trodden on . . . The rattle is a warning to the intruder to keep away. . . . In the same sort of way those who install burglar alarms in their houses put up a notice to that effect outside.' This may be so, but whether it is an established truth or simply an ad hoc hypothesis we are given no real evidence to decide."

In the first place, "Animal Language" was not designed as a scientific monograph, but as a popular book addressed to the general public, so that citations of evidence would have been out of place. In passing, in compiling it I was astonished at the lack of any coherent body of scientific information on the comparative aspect either of sound-production or of hearing: here is a fruitful field for anybody with time and knowledge.

As regards the point concerning the rattlesnake, Gadow, in the "Cambridge Natural History", writes : "The rattle is decidedly useful to the snake as an instrument of warning off any approaching possible enemy, since no snake likes to bite unless in self-defence or in order to kill its prey." The "Encyclopædia Britannica" (eleventh edition) expresses a similar idea. So does that eminent authority, Dr. Thomas Barbour, in his book "Reptiles and Amphibians" (1926), but in considerably greater detail, and with the specific suggestion that the bison is the enemy to be warned off.

Ditmars, in his "Reptiles of the World" (1910), is one of the few authorities to express scepticism as to the rattle's warning function-though he goes on to make the far more speculative statement that it may serve as a mating call, an assertion which, as Barbour points out, must be erroneous as snakes cannot hear.

The whole question of what constitutes "evidence" for the presumed function of an allæsthetic character, whether concerned with warning, threat, or display, is a very interesting one. I have recently briefly discussed this question. It seems clear that there are different degrees of probability, culminating in proof only when the experimental method has been applied, but that the 'old-fashioned' Darwinian view of presuming an adaptive function from general study of the structure and habits of the animal in question gives a reasonable probability and puts the onus of disproof on opponents.

Ditmars indulges in one fallacy that is so common that I cannot refrain from commenting upon it. $\mathrm{He}$ wishes to deny the warning function of the rattle because "many species of harmless and poisonous snakes without a rattle, vibrate their tail when angered". It should surely be obvious by this time that the lack of a character or organ in one type does not preclude its being adaptively functional in another. Numerous examples of this point in regard to threat and warning characters in birds have recently been given by $\mathrm{me}^{2}$. Not only this, but in this particular case the evidence adduced by Ditmars strengthens the case for the warning function of the rattle, by making it clear that tail-vibration per se is a warning device, presumably rendering the snakes more conspicuous without impairing their capacity to strike. In some cases it may produce auditory as well as visual effects, by rustling dry leaves on the ground. The rattle is a further auditory specialization of this widespread generalized activity.

Zoological Society of London,

Regent's Park, N.W.S. March 21.

1 "Evolution" (Oxford, 1938); and Amer. Nat., 72, 416.

${ }^{2}$ Proc. Eighth Internat. Ornith. Congr., p. 430.

\section{Production of Intercellular Hormones}

IN the investigation of metabolic controlling factors (intercellular hormones) appearing in the suspending fluid when cell aggregates are subjected to lethal ultra-violet ${ }^{1}, \mathrm{X}$-rays ${ }^{2}$, and other external agents, it seems to us of particular interest to determine whether such substances are released by living cells into the intercellular fluids or are simply dead-cell disintegration products. To study this question, suspensions of yeast in isotonic salt solution were irradiated with lethal ultra-violet for periods from 9 to 24 hours under such conditions that the full irradiation period was required to kill 90 per cent of the cells. Samples taken out at regular intervals were filtered through Berkefeld filters, and the growth potencies of the filtrates compared with those of filtrates from control suspensions allowed to stand for equal periods without irradiation. The extent of killing was determined by methylene blue staining and by plating. Maximum production of growth factors (intercellular wound hormones) preceded maximum rate of killing and occurred while most of the cells were still living.

As an alternative method, carbon dioxide and oxygen were bubbled through yeast suspensions for 24- and 48-hour periods, and the growth potencies 